\title{
Validation of Finite Element Modeling for Wide and Shallow Reinforced Concrete Beams
}

\author{
Dr. Salah R. Al Zaidee ${ }^{1}$, Abdulraheem K. Awad ${ }^{2}$ \\ ${ }^{1}$ Instructor, College of Engineering, Baghdad University, Baghdad, Iraq \\ ${ }^{2}$ M.Sc. student, College of Engineering, Baghdad University, Baghdad, Iraq
}

\begin{abstract}
This paper aims to validatean ABAQUS finite element model for analysis of wide and shallow reinforced concrete beams. The validation has been achieved through comparison of load deflection curves of the finite element model with those obtained from experimental works of another researcher. After reviewing of related literature, and the experimental work, the finite element model has been prepared in a step-by-step approach. Comparison between load-deflection curves obtained from finite element model with those of experimental works indicates good agreement such that the proposed model can be adopted in future for further studies.
\end{abstract}

Keywords: Wide and shallow reinforced concrete beams, shear strength, finite element method, Abaqus

\section{Introduction}

Wide beams in concrete buildings are usually constructed as hidden beams in the sense that these wide beams have the same depth as the supported floor, especially in the joist construction; thus, they also become shallow members. Wide shallow beams (WSBs) supported on elongated columns are commonly used in residential buildings for construction and architectural advantages, and they have been shown to have some unique characteristics in terms of multidirectional cracking that resembled slabs on columns [1].

Shear strength in reinforced concrete conventional beams, $V_{n}$, inmost reinforced concrete design codes (ACI-318- 08, Eurocode 2 2004) is assumed to be the summation of contributions of concrete and stirrups as expressed by Eq. (1):

$$
V_{n}=V_{c}+V_{s L}
$$

where $V_{c}$ empirically accounts the shear strength of uncracked concrete part, the frictional force due to interlocking, and the rebar dowel action.

This study aims to verify an Abaqus finite element model that proposed to simulate the shear strength for wide shallow reinforced concrete beams. Datafrom Shuraim, [2], have been adopted as the reference experimental works for the validation process. The validated F.E. model may be adopted later by authors or other researchers to investigate other case studies where experimental work is either not possible or costly to execute.

\section{Review of Literature}

The longitudinal and transvers spacing of stirrups studied by many researchers with various methods. Some of the most important researches have been reviewed in below.

Studies by Leonhardt and Walther (1964) as well as Anderson and Ramirez (1989) suggested that welldistributed stirrup legs across the web in a wide beam are important to maintain the necessary vertical equilibrium resultant forces without a concentration of diagonal compression stress [3].

Hsiung and Frantz (1985) tested several beams with different width to depth ratios and concluded that there was no influence of transversal spacing of stirrup legs on shear strength [4].

Anderson andRamirez (1989) tested four simply supported beams using two-,three-, and four-leg stirrups that highlighted the benefits of interiorstirrups on the behavior; however, the loading capacity of the fourbeams did not provide decisive evidence on the spacing role [5].

Serna-Ros et al. (2002) tested 16 simply supported wide shallowbeams, in which the variables included different web reinforcementconfigurations and the support width. Their results showed low efficiencyfor two-leg stirrups and clear improvement when the samearea of stirrups was arranged in multiple-leg configurations [6].

Lubellet al. (2009) reported on two groups of wide beams in which thevariables included different web reinforcement configurations andthe width of the loading plate or support. Their results suggested atrend of decreasing shear capacity as the transverse spacing wasincreased[7].

\section{Experimental Works}

Details of the 16 specimens in the two-span continuous wide shallow beams (CWSB) are provided in Fig. 1, 2. The experimental program was designed with sufficient beam replicate to verify result consistency. The specimens were composed of three groups (I, II, III) based on casting time. Designations of the beams reflect the stirrup configuration as follows: S0 had no stirrups; S1, S2, and S3 had two-leg stirrup configurations as shown Fig. 2.S13 had the combined configuration of $\mathrm{S} 1$ and $\mathrm{S} 3$. The second term in the designation $(75,80,100,150)$ shows the longitudinal spacing of stirrups, and the third term is a serial number (1, 2 , or1 A), in which A is added for partially closed stirrups. The common features include a nominal thickness of 180 $\mathrm{mm}$, a width of $700 \mathrm{~mm}$, and a total length of $3.2 \mathrm{~m}$. All of 


\section{International Journal of Science and Research (IJSR) \\ ISSN (Online): 2319-7064 \\ Index Copernicus Value (2015): 78.96 | Impact Factor (2015): 6.391}

the beams contained the same longitudinal and horizontal transverse rebars with a yield strength of $f_{y}=580 \mathrm{MPa}$. The column size in all groups was the same with a cross-section of $200 \mathrm{~mm}$ by $140 \mathrm{~mm}$ and was cast monolithically with its beam. Its height to the bottom side of the beam was $300 \mathrm{~mm}$ with reinforcement arranged as shown in Fig. 1. The stirrup configurations are shown in Fig. 2, in which a typical leg of stirrups in group I had a bar size of $10 \mathrm{~mm}$, whereas in groups II and III, a typical leg is made of $2 \varnothing 8 \mathrm{~mm}$ for twoleg configuration and $1 \varnothing 8 \mathrm{~mm}$ for four-leg configuration[2].

A $20 \mathrm{~mm}$ maximum aggregate size has been adopted. Concrete cylinders for strength tests were molded, cured, and tested at 28 days in accordance with ASTM standards. The beams were cast in the same orientation as they were later tested. The specimens were wet-cured for seven days under layers of saturated burlap and plastic sheeting. The beams were then exposed to normal atmospheric conditions until the time of testing [2].

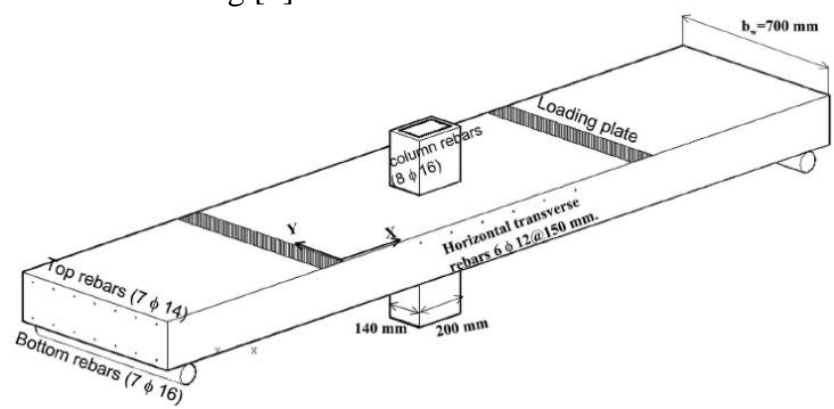

Figure 1: Schematic details of specimen: rebars, supports, loading plates[1].

\begin{tabular}{|c|c|c|c|c|c|c|c|c|c|c|}
\hline $\begin{array}{l}\text { Casting } \\
\text { Group }\end{array}$ & CWSB & $\begin{array}{c}f_{c}^{\prime} \\
\mathrm{MPa} \\
\end{array}$ & \begin{tabular}{|l|}
$f_{y y}$ \\
$\mathrm{MPa}$ \\
\end{tabular} & stirrup configuration & $\begin{array}{c}S_{w} \\
\mathrm{~mm}\end{array}$ & $\begin{array}{r}A_{v_{2}} \\
\mathrm{~mm}^{2}\end{array}$ & $\begin{array}{c}d \\
\mathrm{~mm}\end{array}$ & $\begin{array}{c}s_{L} \\
\mathrm{~mm} \\
\end{array}$ & $\frac{A_{v} d}{s_{L}}$ & $\begin{array}{c}\text { Total } \\
\text { load, kN }\end{array}$ \\
\hline \multirow{4}{*}{ I } & so & 29 & 483 & $\circ \cdots \cdots$ & - & - & 152 & - & - & 474 \\
\hline & $51-80$ & 29 & 483 & $h_{-}$ & 660 & 157 & 152 & 80 & 300 & 644 \\
\hline & $52-80$ & 29 & 483 & 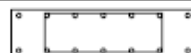 & 440 & 157 & 152 & 80 & 300 & 647 \\
\hline & $53-80$ & 29 & 483 & $\circ$ & 230 & 157 & 152 & 80 & 300 & 677 \\
\hline \multirow{6}{*}{ "I } & so-1 & 28 & & 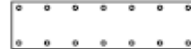 & - & - & 149 & $\cdot$ & - & 470 \\
\hline & S1-75-1A & 28 & 465 & $\square$ & 660 & 201 & 149 & 75 & 400 & 471 \\
\hline & $53-75-1$ & 28 & 465 & & 230 & 201 & 149 & 75 & 400 & 642 \\
\hline & S13-75-1A & 28 & 465 & & 230 & 201 & 149 & 75 & 400 & 800 \\
\hline & 513-100-1 & 28 & 465 & & 230 & 201 & 149 & 100 & 300 & 782 \\
\hline & s13-125-1 & 28 & 465 & . & 230 & 201 & 149 & 125 & 240 & 703 \\
\hline \multirow{6}{*}{ I } & so-2 & 30 & & {$\left[\begin{array}{llllllll} & 0 & 0 & 0 & 0 & 0 & 0 \\
0 & 0 & 0 & 0 & 0 & 0 & 0 \\
\end{array}\right.$} & - & - & 149 & - & - & 464 \\
\hline & $51-75-2$ & 30 & 465 & 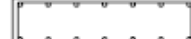 & 660 & 201 & 149 & 75 & 400 & 701 \\
\hline & 53-75-2 & 30 & 465 & & 230 & 201 & 149 & 75 & 400 & 703 \\
\hline & $\$ 13-75-2$ & 30 & 465 & & 230 & 201 & 149 & 75 & 400 & 893 \\
\hline & $513-100-2$ & 30 & 465 & & 230 & 201 & 149 & 100 & 300 & 812 \\
\hline & 513-125-2 & 30 & 465 & & 230 & 201 & 149 & 125 & 240 & 702 \\
\hline
\end{tabular}

Figure 2: Basic data and results of tested beams [2].

\section{Cracking Patterns}

The overall cracking patterns in the tested beams were qualitatively similar in their initial stage, although noticeable variations were observed in the pre-peak and post-peak stages.

\section{Side Cracking Patterns}

Figure 5 shows the cracking patterns on the side of beams. Three types of cracks were observed. Vertical flexural cracks initiated in the bottom side where the flexural stresses were the largest and from the top side along the face of the column attributable to the maximum negative moment. The second type was flexural shear diagonal cracks that formed in RG-2 and extended to the loading plate as well as those developed from the top face in RG-3 and radiated toward the column line. The third type was the horizontal cracks that joined diagonal cracks from the left span and right span; some of them passed by the bottom rebars, acting as splitting cracks. Moreover, in some cases a visible slip was observedalong the column[2].

\section{Surface Cracking Pattern}

On the top surface, diagonal and tangential cracks were observed in all beams; however, their number, width, and orientation varied depending on the load level and stirrup configuration. As an example, Fig. 3showed coalescenceof micro cracks at the top of beam S1-80. For some beams, failure was marked by a plug of concrete that suddenly perforated the portion of the beam above the column. The cracking pattern on the top surface was attributable to the narrow column and it was qualitatively similar to the pattern usually observed in punching shear tests, as reported by several studies. Based on the overall cracking pattern, the mode of failure of these beams was a combination of oneway shear and punching shear[2].

\section{Failure Mods of Beam}

The failure loads for all beams were shown in Error! Reference source not found., and the forms of failure in Figure 5 .

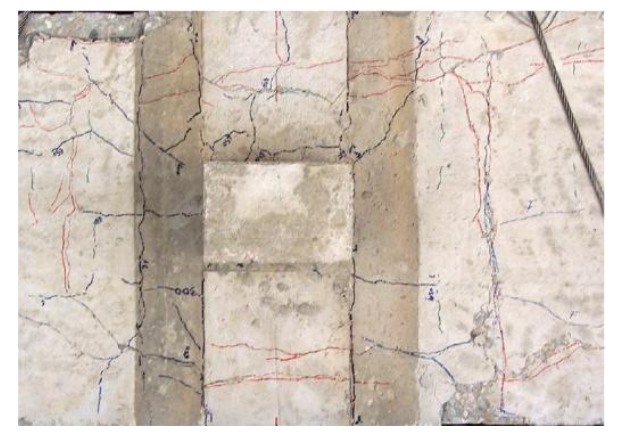

Figure 3: Cracking pattern on the top surface of beam.

\section{Analysis of Stirrup Contributions}

Following the general assumption that shear strength in reinforced concrete beams is the summation of contributions of concrete and stirrups, as given by Eq. (1), it follows that the shear carried by the stirrups, $V_{S T}$ can be extracted approximately [6] [8] as given by Eq. (2).

$$
V_{s T}=V_{u T}-V_{c T}
$$

In which $V_{c T}$ is concrete shear $\mathrm{s}$ of the reference beams without stirrups (S0, S0-1, and S0-2). Accordingly, stirrup effectiveness in resisting shear failure was defined as the 


\section{International Journal of Science and Research (IJSR) \\ ISSN (Online): 2319-7064}

Index Copernicus Value (2015): 78.96 | Impact Factor (2015): 6.391

ratio $V_{S T} / V_{S L}$, in which $V_{S L \text { is }}$ the nominal stirrup contribution defined by Eq. (3), and the results are presented in Table 1. The table shows that by reducing the transverse spacing, higher improvement in efficiency was attained, though no full effectiveness was reached, indicating the need to reduce the transverse spacing even further. For two-leg closed stirrups the average effectiveness ratio was only 0.42 of the theoretical nominal stirrup shear values, $\mathrm{V}_{s L}$. For four-leg stirrups, the average effectiveness ratio was 0.75 of the theoretical nominal stirrup shear values, $V_{S L}$, which represents $80 \%$ improvement in the effectiveness.

$$
V_{s L}=\frac{A_{u} f_{y v} d}{S_{L}}
$$

Table 1: Contribution of Stirrups in Resisting Shear

\begin{tabular}{|c|c|c|c|c|c|c|c|c|}
\hline & \multirow[b]{2}{*}{ CWSB } & \multicolumn{3}{|c|}{ Test data } & \multicolumn{3}{|c|}{ Analysis } & \multirow[b]{2}{*}{ Average efficiency } \\
\hline & & $f_{y v} \mathrm{MPa}$ & $V_{k T} \mathrm{kN}$ & $V_{s \tau} \mathrm{kN}$ & $\frac{A_{y} d}{s_{L}}$ & $V_{\mu \mu} \mathrm{kN}$ & $\frac{V_{s T}}{V_{I L}}$ & \\
\hline \multirow{7}{*}{ Two-leg } & $51-80$ & 483 & 221 & 60 & 300 & 144.2 & 0.42 & 0.42 \\
\hline & $52-80$ & 483 & 222 & 61 & 300 & 144.2 & 0.42 & \\
\hline & $53-80$ & 483 & 232 & 71 & 300 & 144.2 & 0.49 & \\
\hline & S1-75-1A & 465 & 162 & 0 & 400 & 185.7 & $=$ & \\
\hline & 51-75-2 & 465 & 241 & 81 & 400 & 185.7 & 0.44 & \\
\hline & 53-75-1 & 465 & 220 & 59 & 400 & 185.7 & 0.32 & \\
\hline & $53-75-2$ & 465 & 241 & 82 & 400 & 185.7 & 0.44 & \\
\hline \multirow{6}{*}{ Fou-leg } & S13-75-1A & 465 & 274 & 113 & 400 & 185.7 & 0.61 & 0.75 \\
\hline & $513-75-2$ & 465 & 306 & 147 & 400 & 185.7 & 0.79 & \\
\hline & S13-100-1 & 465 & 268 & 107 & 300 & 139.3 & 0.77 & \\
\hline & S13-100-2 & 465 & 278 & 119 & 300 & 139.3 & 0.85 & \\
\hline & S13-125-1 & 465 & 241 & 80 & 240 & 111.4 & 0.72 & \\
\hline & S13-125-2 & 465 & 241 & 81 & 240 & 111.4 & 0.73 & \\
\hline
\end{tabular}

The ineffectiveness of two-leg stirrup layout in resisting shear in wide beams was observed in the studies of [6] and[8] with and without influence of support width. The ineffectiveness is explainable by the need to have a series of trusses across the web in a wide beam to avoid a concentration of diagonal compression stress at few locations [3]; [5].

Recalling that Eq. (3) was formulated on the assumption of full effectiveness, the observed partial effectiveness previously noted leads evidently to a potentially unsafe design because the nominal strength will be unduly exaggerated when the transverse spacing is large.

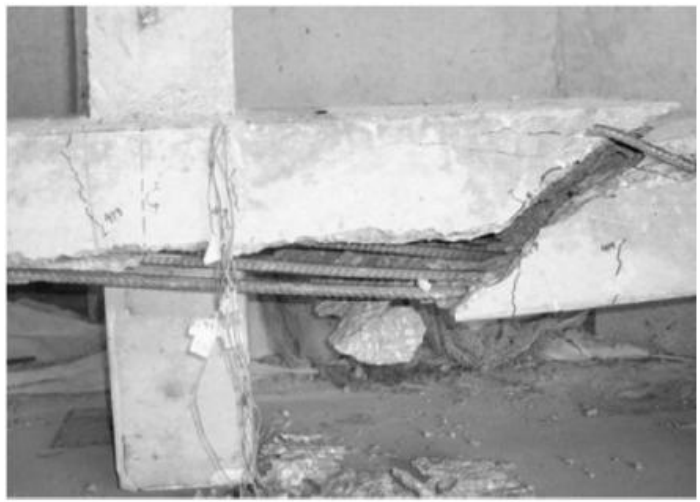

Figure 4: A photo shows beam after failure

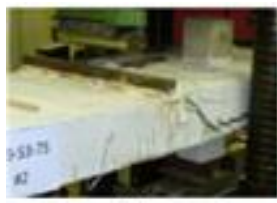

(a)

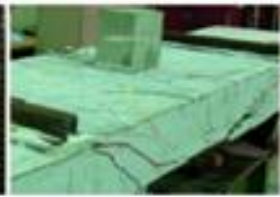

(b)

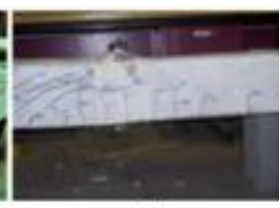

(c)
Figure 5: Side view of three beams showing the major cracking patterns, after failure

\section{Finite Element Modeling}

\section{a) Solid Modeling, Analysis, and Visualization}

The numerical analysis was carried out by using the FE software ABAQUS/Standard. Many commercial programs exist with finite element analysis capabilities for different engineering disciplines. They help to solve a variety of problems from simple linearstatic analysis to nonlinear transient analysis. A few of these codes, such as ANSYS and $A B A Q U S$, have special capabilities to analyze composite materials and they accept custom, user-programmed constitutive equations and element formulations. Since these software packages not only provide analysis tools, geometric modeling, and visualization of results, but also they can be integrated in the larger design, production, and product lifecycle process, they are often called complete analysis environments or computer aided engineering (CAE) systems. Modern FEA software are commonly organized into three blocks: the preprocessor, the processor, and the postprocessor. In the pre-processor block, the model is built defining the geometry, material properties, and element type. Loads and boundary conditions are also entered in the preprocessor, but they may be entered during the solution phase. With this information, the processor block can compute the stiffness matrix and the force vector. In the last block-the post-processor-derived results, such as stress, strain, and failure ratios, are computed. The solution can be reviewed using graphic tools.

Therefore, the first requirement of the model is the geometry. Then, material properties are given for the various parts that make up the geometry. Next, loads and boundary conditions are applied on the geometry. Next, the geometry is discretized into elements, which are defined in terms of the nodes and element connectivity. The element type is chosen to represent the type of problem to be solved. Next, the model is solved. Finally, derived results are computed and visualized [9].

The concrete, internal steel bars were modeled by using the C3D8R linear brick FE, T3D2 linear truss respectively. The embedded region interaction type had been used in modelling the interaction between reinforcement and concrete while the tie type has been adopted to simulate the interaction between the plates and concrete, as indicated in Figure 6.

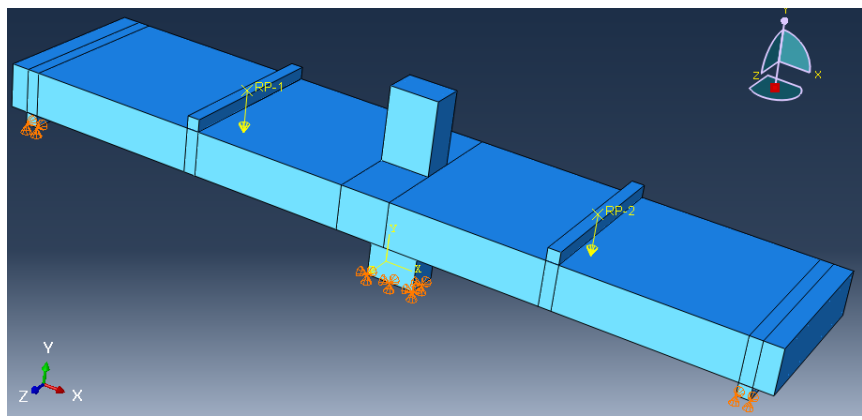

Figure 6: The model in ABAQUS software 


\section{International Journal of Science and Research (IJSR) \\ ISSN (Online): 2319-7064}

Index Copernicus Value (2015): 78.96 | Impact Factor (2015): 6.391

\section{b) Modeling of Geometry}

The modeling of geometry is obtained specifying all nodes, their coordinates, and the element connectivity. The connectivity information allows the program to assemble the element stiffness matrix and the vector of element equivalent force to obtain the global equilibrium equations. There are two ways to generate the geometry model. The first one is to create the mesh manually. The second is to use solid modeling, and then mesh the solid to get the node and element distribution [9]. The second approach has been adopted in this study.

\section{c) Material and Section Properties}

Parts must be associated to materials. Depending on the analysis, material properties can be linear (linear elastic analysis) or nonlinear (e.g. damage mechanics analysis), isotropic or orthotropic, constant or temperature-dependent. Entering the correct materials properties is one of the most important aspects of a successful analysis of composite materials. Other mechanical properties, such as strength, density, and thermal expansion coefficients are optional and their definitiondepends on the objectives of the analysis [2].

All elements need material properties, but structural elements need additional parameters that vary with the type of element. These parameters result from analytical integration of the 3D governing equations while formulating the element. Therefore, besides a Material, one needs to create a Section to provide the additional parameters required by structural elements. In $A B A Q U S$, the additional parameters are called section parameters, [9].

In order to model represents behavior of the concrete the "concrete damage plasticity" has been used [10]. It assumes that the main two failure mechanisms are tensile cracking and compressive crushing of the concrete material. In the linear elastic range the behavior was defined by the elastic modulus $\left(E_{c}=4700 \sqrt{f_{c}^{\prime}}\right)$ calculated according to ACI Code [11], and the Poisson's ratio of 0.15 is assumed.

In the plastic range damage parameters, a description of tensile/compressive behavior were requested. The five plastic damage parameters namely the dilation angle of 40 , the flow potential eccentricity of 0.1 , the ratio of initial biaxial compressive yield stress to initial uniaxial compressive yield stress of 1.16, the ratio of the second stress invariant on the tensile meridian to that on the compressive meridian of 0.667 , and the viscosity parameter of 0.0 have been adopted according to the recommendation[10] and [12].The concrete compressive behavior has been modeled with the well-known stress-strain relationship proposed by EN1992-1-1

The longitudinal and transversal steel bars have been modeled with a bilinear elastic-perfectly plastic model. In the linear elastic range, the behavior is defined by the young modulus of 200,000 MPa and the Poisson's ratio of 0.3.

\section{d) Assembly}

If more than one part exists, assembly is necessary to put the parts together into what is called an assembly, which represents the physical object you are trying to analyze.
During assembly, it is possible to specify how the mesh is related to the parts. That is, the mesh can be dependent or independent of the part. A dependent mesh is tied to the part. So, if the part is used (i.e., instanced) multiple times in an assembly, all the instances of the part will be meshed identically. Moreover, independent mesh means that each instance of the part will have to be meshed independently. The latter provides flexibility to refine the mesh for some instances of the part atthe expense of more work when it comes the time to mesh[9].

\section{e) Reinforcement}

Reinforcement in reinforced concrete structures is typically provided by means of rebars, which are one-dimensional elements (rods) that can be defined a singly or as an embedded in oriented surfaces. With traditional modeling approach, the concrete behavior is considered independently of the rebar. Effects associated with the rebar/concrete interface, such as bond slip and dowel action, are modeled approximately by introducing some "tension stiffening" into the concrete modeling to simulate load transfer across cracks through the rebar.

\section{Defining Rebar in ABAQUS/Standard}

Element-based rebar is usually used to model discrete rebar in beam elements in ABAQUS/Standard. Where one should specify the cross-sectional area and the location of each rebar with respect to the local beam section axis (seeError! Reference source not found.). Each individual rebar must be assigned a separate name in a particular element or element set. This name can be used in defining rebar prestress and output requests [13].

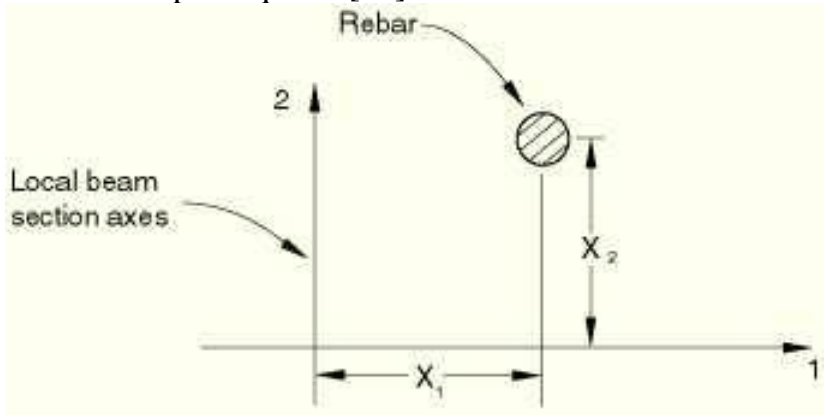

Figure 7: Rebar location in a beam section

\section{1) Embedded elements}

The embedded element technique is:

- Used to specify an element or a group of elements that lie embedded in a group of host elements whose response will beused to constrain the translational degrees of freedom of theembedded nodes (i.e. nodes of embedded elements);

- Can be used in geometrically linear or nonlinear analysis;

- Not available for host elements with rotational degrees of freedom;

- Can be used to model a set of rebar-reinforced membrane, shell, or surface elements that lie embedded in a set of three-dimensional solid (continuum) elements; a set of truss or beam elements that lie embedded in a set of solid 


\section{International Journal of Science and Research (IJSR) \\ ISSN (Online): 2319-7064}

Index Copernicus Value (2015): 78.96 | Impact Factor (2015): 6.391

elements; or a set of solid elements that lie embedded in another set of solid elements;

- Will not constrain rotational degrees of freedom of the embedded nodes when shell or beam elements are embedded in solid elements; and can be imported from ABAQUS/Standard into Abaqus/Explicit and vice versa.

\section{2) Specifying the Host Elements}

By default, the elements in the vicinity of the embedded elements are searched for elements that contain embedded nodes; the embedded nodes are then constrained by the response of these host elements. To preclude certain elements from constraining the embedded nodes, you can define a host element set; the search will be limited to this subset of the host elements in the model. This feature is strongly recommended if the embedded nodes are close to discontinuities in the model (cracks, contact pairs, etc.)[13].

\section{3) Specifying the Embedded Elements}

An embedded element may share some nodes with host elements. These nodes, however, will not be considered to be embedded nodes. Consider the example in Figure 8.
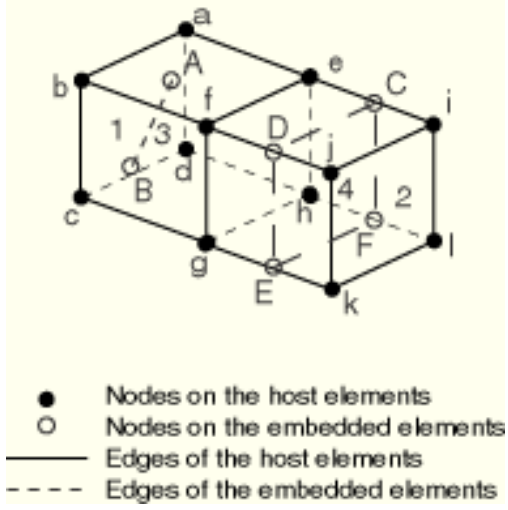

Figure 8: Elements lie embedded in host elements

Elements 3 (truss) and 4 (membrane) lie embedded in elements 1 and 2. Element 1 is formed by nodes a, b, c, d, e, $\mathrm{f}, \mathrm{g}$, and h; element 2 is formed by nodes e, f, g, h, i, j, k, and 1 ; element 3 is formed by nodes $\mathrm{A}$ and $\mathrm{B}$; and element 4 is formed by nodes $\mathrm{C}, \mathrm{D}, \mathrm{E}$, and $\mathrm{F}$. If the host element set includes elements 1 and 2 and the embedded element sets contain elements 3 and 4 , respectively, Abaqus will attempt to find if there are any embedded nodes $(\mathrm{A}, \mathrm{B}, \mathrm{C}, \mathrm{D}, \mathrm{E}$, and F) lying within host elements 1 or 2 . If node $A$ is found to be lying close to the a-b-f-e face of element 1 , all the degrees of freedom at node $\mathrm{A}$ are constrained to nodes $\mathrm{a}, \mathrm{b}, \mathrm{f}$, and e, with appropriate weight factors being determined based on the geometric location of node A in element 1. Similarly, if node $\mathrm{B}$ is found to be lying inside element 1 , and node $\mathrm{E}$ is found to be lying close to the $\mathrm{g}-\mathrm{k}$ edge of element 2, respectively, all the degrees of freedom at node $\mathrm{B}$ are constrained to nodes a, b, c, d, e, f, g, and h, and all the degrees of freedom at node $\mathrm{E}$ are constrained to nodes $\mathrm{g}$ and $\mathrm{k}$, with appropriate weight factors being determined based on the geometric location of node $\mathrm{B}$ in element 1 and the geometric location of node $\mathrm{E}$ on the $\mathrm{g}-\mathrm{k}$ edge of element 2, respectively. Therefore, one should make sure that all the nodes on the embedded elements are properly constrained to nodes on the host elements[13].

\section{f) The Finite Element Mesh}

In order to obtain accurate results from the FE model, all the elements in the model were purposely assigned the same mesh size to ensure that each two different materials share the same node. The type of mesh selected in the model is structured. The mesh element for concrete is 3D solid which is called C3D8R and for the rebar it is 2D truss which is called T3D2 (Figure 9).

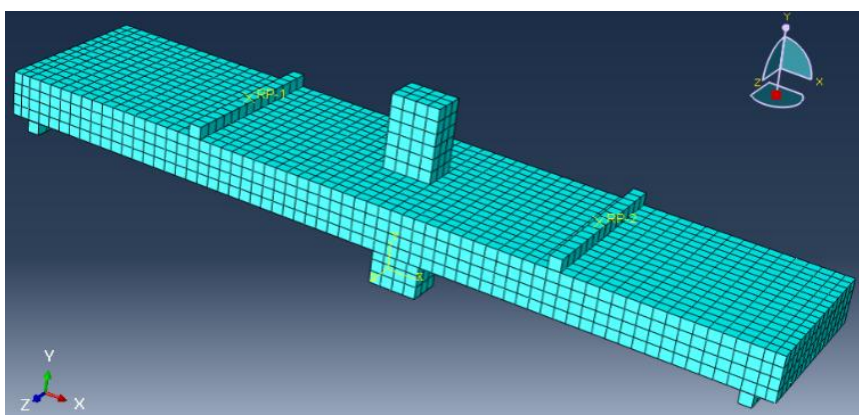

Figure 9: The mesh of model with ABAQUS software

\section{g) Applying of Loads and Solution Technique}

In structural analysis, loads are defined by forces, pressures, inertial forces (as gravity), and specified displacements, all applied to the model. Specification of different kinds of loads for the FE model is explained in the following sections. The reactions obtained by fixing a nodal degree of freedom (displacements and rotations) are discussed also.

Loads can be applied on nodes by means of concentrated forces and moments. Also, loads can be distributed over the elements as: surface loads, body loads, inertia loads, or other coupled-field loads (for example, thermal strains).

A surface load is a distributed load applied over a surface, for example a pressure. A body load is a volumetric load, for example expansion of material by temperature increase in structural analysis. Inertia loads are those attributable to the inertia of a body, such as gravitational acceleration, angular velocity, and acceleration.

A concentrated load applied on a node is directly added to the force vector. However, the element interpolation functions are used to compute the equivalent forces vector due to distributed loads.

The analysis process is normally broken down into several steps, each representing different loading and constraint conditions. The minimum number of steps are two: an initial step and at least one additional step. No loads can be applied on the initial step, only boundary conditions [9].

\section{Load Deflection Curve at Mid-span}

Deflection was measured at mid-span at the center of the bottom face of the beam.Figure 10, Figure 11, Figure 12, and Figure 13shows the load deflection curve of the beam for both the experimental and numerical data. In general, the load deflection curve for the beam from the numerical results has good agreement with the experimental data. 
International Journal of Science and Research (IJSR)

ISSN (Online): 2319-7064

Index Copernicus Value (2015): 78.96 | Impact Factor (2015): 6.391

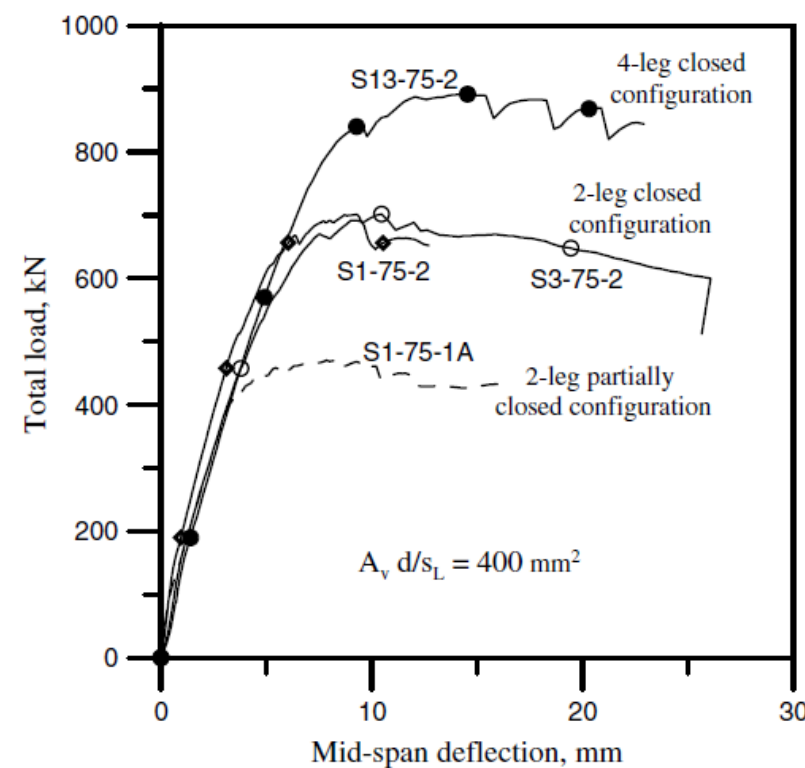

Figure 10: Load-deflection relationships for beams with equal amount of stirrups

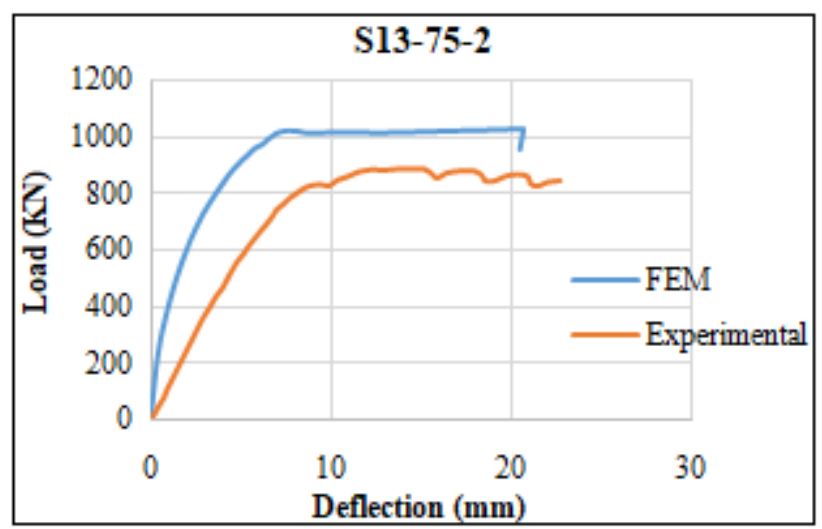

Figure 11: Load-Deflection curve beam S13-75-2

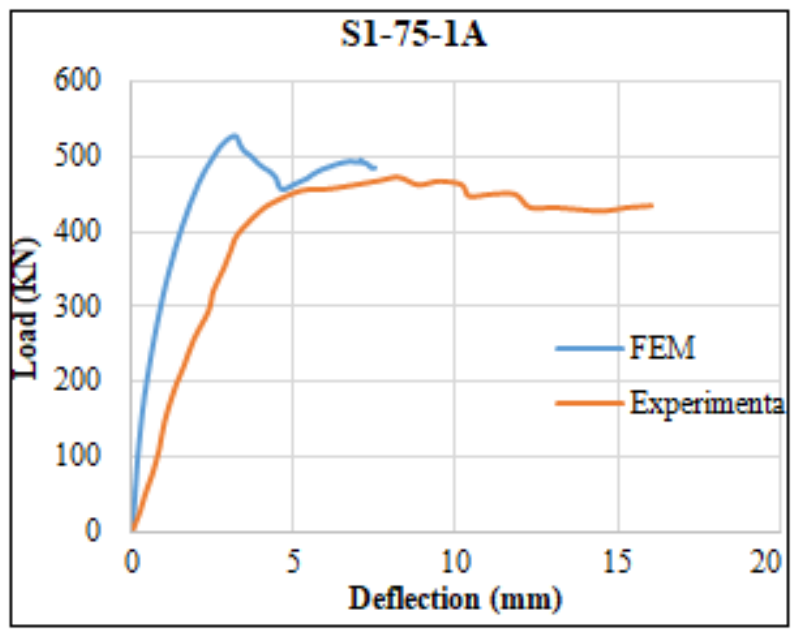

Figure 12: Load-Deflection curve beam S1-75-1A

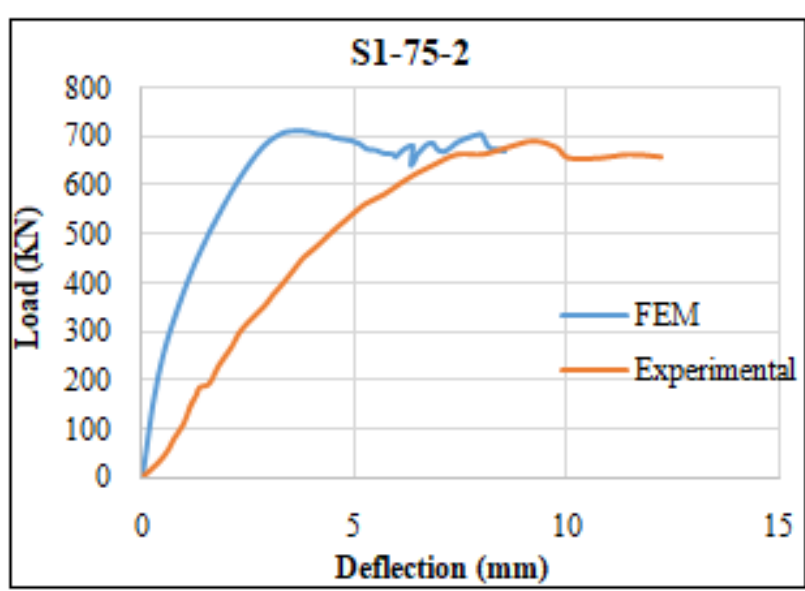

Figure 13: Load-Deflection curve beam S1-75-2

\section{Conclusions}

This paper aims to validate a finite element model to be use in analysis of wide shallow reinforced concrete beams. The validation procedure has based on comparison of loaddeflection curves obtained from the numerical FE model with those obtained from experimental work of Shuraim [2].

The comparison indicates a good agreement between of FE and experimental results. Therefore the proposed FE model including modeling of geometry, material, assembly, meshing, and applying of load can be adopted in future works with adequate confidante.

\section{Acknowledgements}

At first and before everything, praise be to Allah. Without Allah guidance and help we could not have presented this work. The authors would like to thank the staff of Civil Engineering Department in College of Engineering/University of Baghdad for their encouragement and support during preparation of this study.

\section{References}

[1] A. I. a. S. A. B. AL-Negheimish, "Structural design and construction of residential in Riyadh,," in world housing congress, Terengganu, Malaysia, 2007.

[2] A. Ahmed B. Shuraim, "Transverse Stirrup Configurations in RC Wide Shallow Beams Supported on Narrow Columns," Journal of Structural Engineering, vol. 138, no. 3, pp. 416-424, 2012.

[3] F. a. W. Leonhardt, The stuttgart shear tests 1961., London, UK: Cement and Concrete Association,, 1964.

[4] W. a. F. G. C. Hsiung, "Transverse stirrup spacing in $\mathrm{R} / \mathrm{C}$ beams," Journal of structural engineering, vol. 111, pp. 353-362, 1985.

[5] N. S. a. R. J. A. Anderson, "Detailing of Stirrup Reinforcement," ACI Structural Journal, vol. 86, no. 5, pp. 507-515, 1989.

[6] P. F.-P. M. A. M.-S. P. a. D. O. A. R. Serna-Ros, "Influence of stirrup distribution and support width on the shear strength of reinforced concrete wide beams," Magazine of Concrete Research, vol. 54, no. 3, pp. 181191, 2002. 


\section{International Journal of Science and Research (IJSR) \\ ISSN (Online): 2319-7064}

Index Copernicus Value (2015): 78.96 | Impact Factor (2015): 6.391

[7] A. S. B. E. C. a. C. M. P. Lubell, "One-way shear in wide concrete beams with narrow supports," in Structures Congress, 2008.

[8] A. S. B. E. C. a. C. M. P. Lubell, "Shear Reinforcement Spacing in Wide Members," Structural Journal, vol. 106, no. 2, pp. 205-214, 2009.

[9] E. J. Barbero, Finite Element Analysis of Composite Materials Using AbaqusTM, West Virginia: Taylor \& Francis Group, LLC, 2013.

[10] J. Lubliner, J. Oliver, S. Oller and E. Oñate, "A plastic damage model for concrete," International Journal of Solids and Structures, vol. 25, no. 3, pp. 299-326, 1989.

[11]A. C. 318, Building code requirements for structural concrete and (ACI 318-14) commentary, American Concrete Institute, 2014.

[12] K. a. S. I. Hibbitt, ABAQUS Finite Element Code (2011), USA: Pawtucket, RI, 2011.

[13] Abaqus Analysis User's Manual. 